\title{
O INFRA-ORDINÁRIO NA PAISAGEM URBANA COMO CONDIÇÃO DA PRODUÇÃO DE ETNOGRAFIAS SONORAS E VISUAIS
}

\author{
Ana Luiza Carvalho da Rocha \\ Cornelia Eckert
}

\begin{abstract}
Abertura
Este texto-paper não se sustenta na solidão. Ele depende de uma obra, a de Georges Perec, e está amarrado a um documentário. Que seja então ligado o vídeo, por favor, para exibir de Roberto Bober e textos de Georges Perec uma vinheta dos 49 minutos NTSC SP cor 1992, França1 do filme "En remontant la rue Vilin".

O paper refere-se igualmente a nossas notas de campo e reminiscências de experiências etnográficas realizadas em Paris em 2001, quando por uma sorte CeNePeQuiana e CAPESiana, estávamos ambas em pesquisa pós-doutoral no tradicional bairro parisiense Belleville, um território oriundo de trocas sociais pluriétnicas acumuladas no tempo e, mais, espaço de nossa morada, por outras sortes e por outras histórias não científicas. O projeto de pós-doutorado consistia no inventário de filmes documentários sobre o mundo urbano contemporâneo, estudo de roteiros fílmicos sobre o cotidiano, estilos de vida e personagens citadinos, assim como desenvolvimento de etnografia no cenário urbano parisiense.

O encontro com a obra literária de Georges Perec, tanto quanto com os documentários de e sobre este autor (ver no final do texto), aconteceu a partir do trabalho de pesquisa no acervo audiovisual do "Forum des Images" em Paris. Entre eles, destacamos aqui o documentário "En remontant la rue Vilin" de Roberto Bober, lançado após a morte do escritor, no qual o documentarista destaca a figura de Perec como um investigador do cenário urbano parisiense, diríamos nós, um "etnógrafo" nas ruas desta cidade.

\section{Uma Antropologia que evoca o nós}

Familiarizadas com alguns documentários sobre a cidade de Paris, descobrimos maravilhadas o documentário de Georges Perec, "Remontant la Rue Vilin", de R. Bober, para, logo após, mergulharmos nas leituras de algumas de suas obras, em especial Espèces d'Espaces (1974/2000) e L'infra-ordinaire (1989). Todas essas obras, por razões diferentes, nos motivaram a realizar uma proposta de etnografia nas ruas parisienses a partir de abril de 2001. Tratava-se de uma aventura urbana despretensiosa para reinventar nosso

\footnotetext{
${ }^{1}$ Documentário produzido a partir de 500 fotografias obtidas por Perec ao longo de várias décadas. O filme deseja documentar o desaparecimento deste lugar tão caro ao escritor Georges Perec, religando estes restos históricos à sua obra e à sua biografia. Os realizadores utilizam-se da escritura fílmica a fim de "nomear para salvar do esquecimento". Perec, famoso escritor francês, parte de fotografias de época para buscar um reencontro com o bairro e a rua de sua infância, que foram transformados ao longo do processo de reurbanização parisiense.
} 
olhar sobre os territórios desta cidade por nós conhecida desde nosso período de doutoramento ao longo dos anos 1990. Dentre muitos, um lugar particularmente nos seduz por sua heterogeneidade de "universos simbólicos" e "províncias de significados". O contexto é o quartier de Belleville, fronteira cultural entre o $13^{0}$ arrondissement e o seu vizinho, o $20^{\circ}$ arrondissement de Paris.

$\mathrm{O}$ alinhamento paralelo de duas séries de prédios determina o que chamamos de uma rua: a rua é limitada por um espaço de casas, geralmente em seus dois lados mais longos; a rua é aquilo que separa as casas entre si, seja ao longo da rua, seja atravessando-a. Além disto, a rua é o lugar a partir do qual apreendemos as casas. Há muitos sistemas de observação; o mais conhecido nos dias de hoje e, de acordo com nosso ambiente, consiste em dar um nome a rua e atribuir números às casas...". T.A. (PEREC, 1974/2000, p. 93-94).

Nossa tentativa era localizar, passado mais de 30 anos, as possíveis ruas do percurso que Perec havia realizado. Assim, como seu trajeto, o nosso percurso em busca da Rua Vilin era também descontínuo no tempo da observação. Éramos momentaneamente habitantes da cidade de Perec, problematizando, ao longo de nossa caminhada, o desaparecimento dos rastros deixados pelo escritor nas suas obras L'infra-ordinnaire e Espèces d'espaces, e retomado no documentário de R. Bober. A intenção era, então, re-atualizar o percurso mapeado pelos seus escritos com a ajuda de um guia das antigas ruas de Paris e um mapa atual da cidade, e munidas de máquina fotográfica digital, cartografar estes itinerários.

\section{Uma rua tão}

cinza em sua modernidade-higiênica que hesitamos em fotografar. O clic é feito em digital, acho que foi Cornelia, ou terá sido Ana? Lembramos da pergunta de um bolsista de iniciação científica do Biev: "Qual

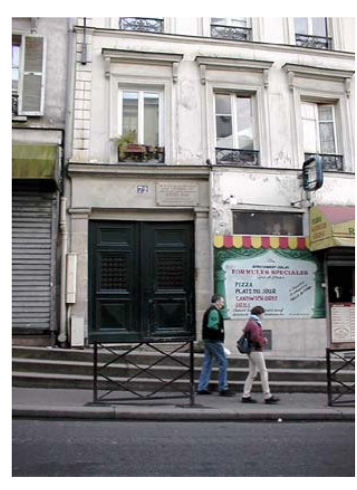
a diferença da pesquisa etnográfica individual e esta que fazemos aqui em equipe, ou a que vocês

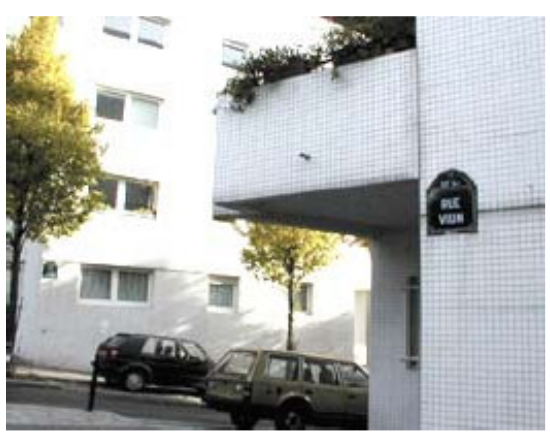
fizeram em Paris, em dupla?" A pesquisa em dupla não confunde os seres. Trajetórias urbanas e intelectuais convergentes, porém realizadas por pessoas diferentes. As modalidades de projetos acadêmicos são familiares, os interesses pessoais se cruzam em leituras diversas, reminiscências estranhas de duas indefinidas personalidades.

Lembranças das caminhadas em Belleville cuja pertinência como campo de investigação fora sugerida pelo proprietário do apartamento alugado, motivando-nos com entusiasmo à pesquisa neste bairro que abrigava suas lembranças de juventude, alegando o estilo boêmio do bairro famoso por ter sido a morada de artistas como Edith Piaf, e por acolher personagens "exóticas" dadas as qualidades pluriétnicas do contexto e sociabilidades efervescentes entre diferentes grupos urbanos. As pesquisadoras não esquecem uma certa dose de emoção ao adentrar "bakhtinianamente" na circularidade da memória narrada por Perec. Só alcançamos as franjas das reminiscências escritas por Perec, 
os rastros na cidade, que como caminhantes atualizamos, numa "retórica da caminhada", entre o lá e o cá. Ou, nos termos bachelardianos, entre o dentro e o fora ${ }^{3}$, como nos ensinou o mestre da dialética da duração.

Contrariamente ao que se processa usualmente, uma etnografia da lembrança do passado, ou seja, o estudo da (ECKERT e ROCHA, 2001), aceita matéria das lembranças ou tempo vivido adquiram uma elas se submetem às que encerra o tempo pensado. com as quais opera a às falhas do tempo, é que são propagação de uma memória, social, ou ainda coletiva. nos seus escritos Espèces documentário de Bober retrata fílmica: "não se pode reviver o encadeamento num tema presente." "Reviver o tempo

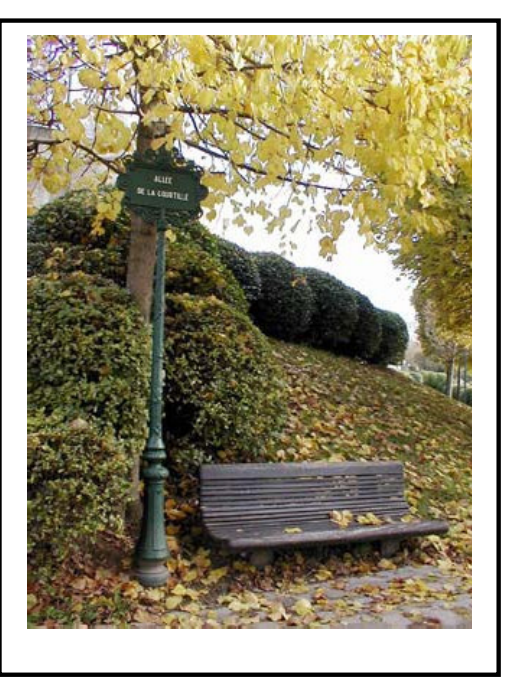
etnografia da duração como suposto que a reminiscências de um substância somente se ondulações do próprio ato Tais ondulações rítmicas, inteligência humana face as responsáveis pela seja individual, seja Assim como revela Perec, d'espaces, e que o tão bem na linguagem passado sem 0 afetivo necessariamente desaparecido é apreender a inquietude de nossa própria morte". Desta forma, "só nos recordamos de algo ao proceder a escolhas, ao decantar a vida turva, ao recortar fatos da corrente da vida para neles colocar razões". (BACHELARD, 1988, p. 51).

Finalmente, Georges Perec, na sua obra L'infraordinnaire, lança a proposta de se fundar uma antropologia do nós, aquele que, finalmente, falará de nós, que irá procurar em nós mesmos aquilo que há longo tempo foi pilhado dos outros. Prosseguindo nesta linha de argumentação, o poeta se indaga: Como, então, nos darmos conta da nossa vida ordinária, da nossa rotina? Como interrogar nosso cotidiano? Como descrevê-lo?

Não se trataria mais do exótico, mas do "endótico" (Perec, 1989, p. 12). Não mais do extraordinário, mas do infra-ordinário. Enunciar os contextos e ritmos do viver cotidiano numa metrópole é o que seus escritos mimetizam na busca do sentido, na descoberta antropológica da cidade e seus espaços multiplicados, divididos e diversificados. $\mathrm{O}$ olhar etnográfico se deposita, então, na cidade como parte constitutiva da identidade narrativa dos seus habitantes e dos itinerários de seus movimentos e deslocamentos nas aglomerações urbanas. Apropriando-nos dos comentários de Teresa Caldeira, "Cidade de Muros" (2003), sobre sua experiência etnográfica em São Paulo, também como em Georges Perec, não é a Alteridade que estrutura a indagação metodológica, mas é o seu deslocamento numa tentativa de inventariar "as relações que são estabelecidas entre as pedras e os homens",

\footnotetext{
${ }^{2}$ Cf. este autor “(...) deve-se acrescentar que esta localização (cá-lá) necessariamente implicada pelo ato de andar e indicativa de uma apropriação presente do espaço por um 'eu' tem igualmente por função implantar o outro relativo a esse 'eu' e instaurar assim uma articulação conjuntiva e disjuntiva de lugares (...)". (DE CERTEAU, 1994, p. 178), assim, “(...) o caminhante constitui, com relação à sua posição, um próximo e um distante, um cá. E um lá".

3 “Ainsi, dans l'être, tout est circuit, tout est detour, retour, discours, tout est chapelet de séjours, tout est refrain de couplets san fin" (BACHELARD, 1984, p. 193).
} 
para aludir a reflexão sobre a memória coletiva e o espaço de Maurice Halbwachs (1990, p. 136). ${ }^{4}$

A perspectiva defendida nesta obra, por Perec encontra pertinência científica na busca de uma regra ao olhar que observa, organiza, interpreta a cidade e seus territórios para lançar-se na estética poética de um relato denso que aciona "um saber que tem por forma a duração de sua aquisição e as coleções intermináveis dos seus conhecimentos particulares". (DE CERTEAU, 1994, p. 157).

Em nosso intento de etnografar o quartier de Belleville, em Paris, ecoa a voz de Georges Perec, permitindo-nos a inquietante familiaridade de caminhar no seu velho bairro para proceder, pelos jogos da memória coletiva, ao inventário de nós mesmas.

\section{Os fios da trama de uma pesquisa}

Clima ensolarado e frio. Nossa paixão de brincar de flanêur é séria, é científica, não duvidem disso. Em nossas mentes e nos diálogos das caminhadas, a intenção segue a idéia, nascida em 1997, de traduzir a interpretação de uma cultura urbana a partir da sua expressão nos termos de etnografias na rua, inspiradas na figura do flanêur proposta por Walter Benjamin e na prática de observation flottante de Colette Pétonnet. Etnografias de rua que resgatam alguns tópicos da idéia do tratamento direto de apreensão da realidade do cinema de Jean Rouch, mestre do nosso orientador na França, o cineasta antropólogo Jean Arlaud.

Nem tão oposta à experiência realista e empírica da ancienne anthropologie, pois não rompemos com ela, a etnografia de rua remontaria a uma tradição dentro da Antropologia, como parte integrante de sua proto-história. Por outro lado, reflexão constante em uma disciplina que sempre se renova. Não se trata, aqui, de uma invenção de prática da pesquisa antropológica, nem tão pouco advogamos uma patente pela originalidade para o termo "etnografia de rua". A mágica etnográfica está alhures e basta que se freqüente as crônicas, literaturas $^{5}$ e, sobretudo bons relatos dos viajantes que inventaram a fórmula do deslocamento, do olhar subjetivo, da antropologia compartilhada dos nossos viajantes ao estranho lugar como Malinowski, Lévi Strauss, Evans-Pritchard, Jean Rouch, Clifford Geertz, Paul Rabinow, entre outros, ou nossos descolonizadores da duração urbana como

\footnotetext{
4 "Se entre as casas, as ruas, e os grupos de seus habitantes, não houvesse apenas uma relação inteiramente acidental, e de efêmera, os homens poderiam destruir suas casas, seu quarteirão, sua cidade, reconstruir sobre o mesmo lugar uma outra, segundo um plano diferente; mas se as pedras se deixam transportar, não é tão fácil modificar as relações que são estabelecidas entre as pedras e os homens. Quando um grupo humano vive muito tempo em lugar adaptado a seus hábitos, não somente os seus movimentos, mas também seus pensamentos se regulam pela sucessão das imagens que lhe representam os objetos exteriores. Eliminai agora, eliminai parcialmente ou modificai em sua direção, sua orientação, sua forma, seu aspecto, essas casas, essas ruas, essas passagens, ou mudai somente o lugar que ocupam um em relação ao outro. As pedras e os materiais não vos resistirão. Mas os grupos resistirão, e, deles, é com a própria resistência, senão das pedras, pelo menos de seus antigos arranjos na qual vos esbarreis. Sem dúvida, essa disposição anterior foi outrora obra de um grupo. O que um grupo fez, um outro pode desfaze-lo. Mas o desígnio dos antigos homens tomou corpo dentro de um arranjo material, quer dizer dentro de uma coisa, e a força da tradição local veio da coisa, da qual era a imagem. Tanto é verdade que, para toda uma parte deles mesmos, os grupos imitam a passividade da matéria inerte". (HALBWACHS, 1990, P. 136 e 137).

${ }^{5}$ Paulo Bentancur em recente artigo na Zero Hora aponta inúmeras literaturas que fazem parte da nossa paisagem mental para interpretar o viver citadino como Paris é uma Festa de ficção de Hemingway, Dublinenses, contos de James Joyce; Montevideanos, contos de Mario Benedetti; The Buenos Aires Affair, romance de Manuel Puig; A Arte de Andar nas Ruas do Rio de Janeiro, conto de Romance Negro, de Rubem Fonseca; Mistérios de Porto Alegre, contos e crônicas de Moacyr Scliar, Mongólia, romance de Bernardo Carvalho, Espanha de Cervantes, Londres de Dickens, Paris de Balzac, Rio de Janeiro de Machado de Assis e de Lima Barreto, As Cidades Invisíveis, de Ítalo Calvino, poemas de Mario Quintana, sobretudo em A Rua dos Cataventos, Fervor de Buenos Aires, de Jorge Luis Borges; Os Ratos, de Dyonélio Machado; Em Caminhos Cruzados, O Resto é Silêncio e Noite, de Erico Veríssimo.
} 
Roger Bastide, Antônio Cândido, Gilberto Velho, Tereza Caldeira, Antonio Augusto Arantes, etc. para dar conta do incognoscível e do inteligível em nossa própria cidade, colocadas no sótão ou guardadas no porão bachelardiano das muitas antropologias.

O antropólogo Michel Leiris, autor da obra Afrique Fantôme, foi um dos inspiradores de sua obra, confidencia Perec. Este, ao contrário, lançou-se à aventura das palavras e, ao final, a escrita o tornou narrador, conhecido pelos poetas por sua lipogramática e sua dedicação a jogos verbais, um oulipiano, como sua obra "O Desaparecimento" (1969). A análise de sua obra e sua vida resulta em uma quantidade expressiva de dissertações, teses, livros, artigos, associação de admiradores e home pages. ${ }^{6}$ Raymond Queneau (1903-1976) lhe inspirou o garimpo da memória, na investigação dos rastros dos espaços em sua banalidade. O que buscar? Trata-se de aplicar um método. Sistemático e meticuloso que G. Perec aborda em Espèce d'espace a fim de conhecer a cidade. Fazer um inventário do que se vê. Recenseamento e análise de distinções, comparações, o que é a cidade e o que não é a cidade? Olhar, reconhecer, conversar com as pessoas, indagar aos transeuntes ou estabelecidos. Pensar na trajetória da própria cidade, na sua história, o que foi, o que é. O método, como sugere o escritor (1974/2000, p. 122), é de desconfiar dos discursos e das afirmações, desconfiar de suas próprias pré-concepções.

Sem dúvida, etnologizamos, aqui, a arte de saber-fazer de Georges Perec, posto que, não se trata unicamente de ler sua escritura. Mas de descobrir seu tom "etnográfico" através da obra filmica de Bober, na forma como o cineasta reinventa a escrita do poeta como parte de um método de investigação, de grande valor heurístico para os estudos que vimos desenvolvendo sobre memória coletiva e estética urbana no mundo contemporâneo e que nos aponta para a função de eufemização, enquanto "projeto imaginário", que "tenta melhorar a situação do homem no mundo" (DURAND, 1988, p. 101).

Por efeito de espelho, na etnografia do quartier de Belleville é de Porto Alegre que queremos falar, e também de Recife e de Olinda, de São Paulo, de Maceió, de Florianópolis e Cachoeira do Sul, assim como Nova York, Santiago do Chile, Buenos Aires e

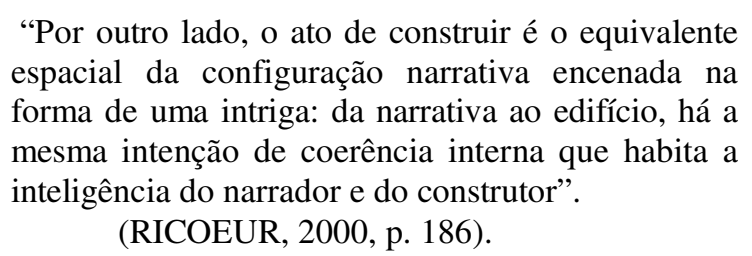
espacial da configuração narrativa encenada na forma de uma intriga: da narrativa ao edifício, há a mesma intenção de coerência interna que habita a inteligência do narrador e do construtor". (RICOEUR, 2000, p. 186). tantas outras cidades que nos povoam com seus fenômenos urbanos e que fazem parte de nosso percurso de pesquisa. Cidades como outras tantas, iguais e diferentes daquelas que os pensadores da Escola de Chicago souberam conceitualmente nos instigar. Lugares de passagem e território de experiências de etnografia de rua, na linha de pesquisa proposta em artigo acolhido pela Revista Studium ${ }^{7}$.

Uma prática de pesquisa no contexto urbano que encontra inspiração na trilogia de Paul Ricoeur, Tempo e Narrativa, e na fenomenologia bachelardiana de obras como $A$ Poética do Espaço e a Dialética da Duração. Nela, a cidade desponta como um tecido complexo de deslocamentos e itinerários de seus habitantes, herdeiros de tempos narrados e espaços construídos por uma comunidade urbana ao longo do tempo, e se exprime na trama das resistências e das contestações dos grupos às suas transformações. Os modos de vida se configuram, então, como intertextualidade de narrativas que renovam, repetem,

\footnotetext{
${ }^{6}$ Na Folha de São Paulo - 3/1/1999, naquela mania de fazer os balanços do século XX, ficou em 59 lugar entre os mais importantes dos escritores do século com sua obra “A Vida - Modo de Usar” de 1978. Nasceu em 1936 e morreu em 1982.

${ }^{7}$ Referimo-nos, aqui, à revista eletrônica organizada por Fernando de Tacca (número 8).
} 
permanecem. A cidade, a rua, o bairro nos habita como espaço vivido, como a profundeza de um poema.

\section{A arte de narrar as metamorfoses do cotidiano urbano}

Trata-se de não reduzir a descrição de Perec a um objeto textual, mas de procurar compreender as artes de narrar, pelas quais o escritor construiu eficazmente uma texturologia dos lugares cotidianos de uma grande metrópole, familiarizando o leitor com a rua de sua infância ao mesmo tempo em que o situa na memória do lugar, do quartier parisiense de Belleville.

A escrita de Georges Perec interroga o habitual ao descrever a sua rua de infância. Um olhar que interroga, ora distanciado, ora afetivo, as ruas do bairro, e que gera escritos sistemáticos ainda que triviais e fragmentários sobre as fachadas das casas e dos imóveis, os calçamentos, os moradores locais. Interroga-se, mas a ponto de descobrir em si aquilo que esqueceu desde as origens. Personagem e cenário se fundem numa alquimia de reminiscências ao reinventar a cidade como interlocutora de suas memórias.

Camadas de tempo se revelam no

1

A Rua Vilin

Quinta-feira 27 fevereiro 1969,

próximo às 16 horas

A Rua Vilin começa na altura do número 29 da Rua des Courrones, em face de imóveis novos, os

recentes HLM que já trazem em si alguma coisa de velho.

(Perec, 1989, p.15) diário que identifica a cartografia das ruas. Acontecimentos observados, a música ao longe, as crianças jogando, os algerianos superlotando o velho café no 22, os carros da polícia (CRS) estacionados no Boulevard de Belleville, acontecimentos observados que evocam os acontecimentos noticiados: incidentes graves entre judeus e árabes na região.

Inventário do cotidiano, o infra-ordinário se traduz numa cartografia de casas e ruas observadas e no registro de paisagens sonoras. Lembremos aqui algumas passagens deste inventário da fuga do tempo: Quinta-feira, dia 27, ano 1969, os imóveis de números 1, 2, 3 da Rua Vilin foram recentemente demolidos. Quinta-feira, dia 27, ano 1970, toda um quarteirão de casas foram destruídas na esquina da Rua des Couronnes. Não se pode subir a Rua Vilin, este sentido é proibido. Novos imóveis surgem. Ainda permanecem em pé os antigos números 1,2 e 3 , onde $\mathrm{G}$. Perec assinala que um homem o observa da sua janela. Um outro o confunde com físcal: "Então, veio para nos destruir?". A caminhada prossegue: 5, 6, 7 ... Registro de sons de uma música árabe ao fundo. Cafés, leiterias, tinturarias. Casas de reparos, consertos, cabeleireiros. Lugares, abertos, imóveis fechados. Alguns apartamentos com vida, outros abandonados, murados. Do 41 ao 49 , quase todos os prédios são murados. Número 20, casa condenada. Números 21 e 23 mais casas abandonadas. A

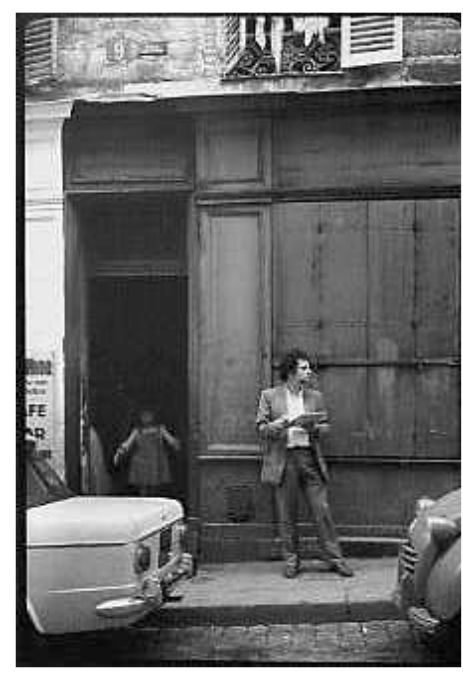
descrição segue um tom monótono: antigo açougue, antiga casa de alimentação, antigo café, antigo hotel. Quarta-feira, 13 de janeiro de 1971. Os números 25, 27: lojas fechadas; a partir do 27: muros. O número 32: Vinhos e licores fechado. Os números 34 e 36 estão 
abandonados, são cortiços. Os números 53-55 (Le repos de la Montagne, vinhos) estão fechados. Logo acima, terrenos vagos.

Belleville, a Paris vetusta cedeu aos imperativos da lógica moderna haussmaniana em espaços geométricos do urbanista e do arquiteto. Outras regularidades se sucedem, menos panópticas, menos sombrias, com casas remodeladas aos pés de um grandioso Jardim Belleville que permite o abraço panorâmico da cidade.
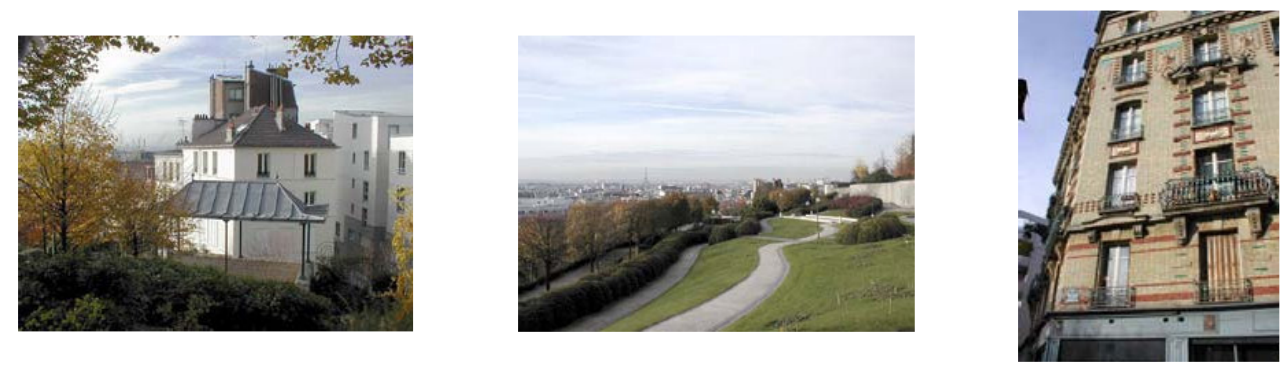

Agosto de 2001. A nossa caminhada revela poucas resistências da matéria morta. Nenhuma ruína. O patrimônio transformado é de novo espaço vivido, das mesmas e de outras práticas, dos mesmos e outros procedimentos. A etnografia de rua de Georges Perec tece as mortes, os lutos e o renascimento de uma parte da paisagem de seu bairro de infância, Belleville. Sua descrição atualiza os espaços vividos dando existência afetiva ao bairro no seu estranhamento ao tempo.

Por que a narrativa do poeta nos interessa como lógica dramática? Porque sua voz, sua escrita fala de uma cidade, um bairro, uma rua cuja transformação de sua matéria sacrificada por atos de destruição desloca, incomoda, modifica e perturba as lembranças de Georges Perec que, diferentes de seus antigos moradores, não se acham implicadas na morte cotidiana de seus territórios de vida.
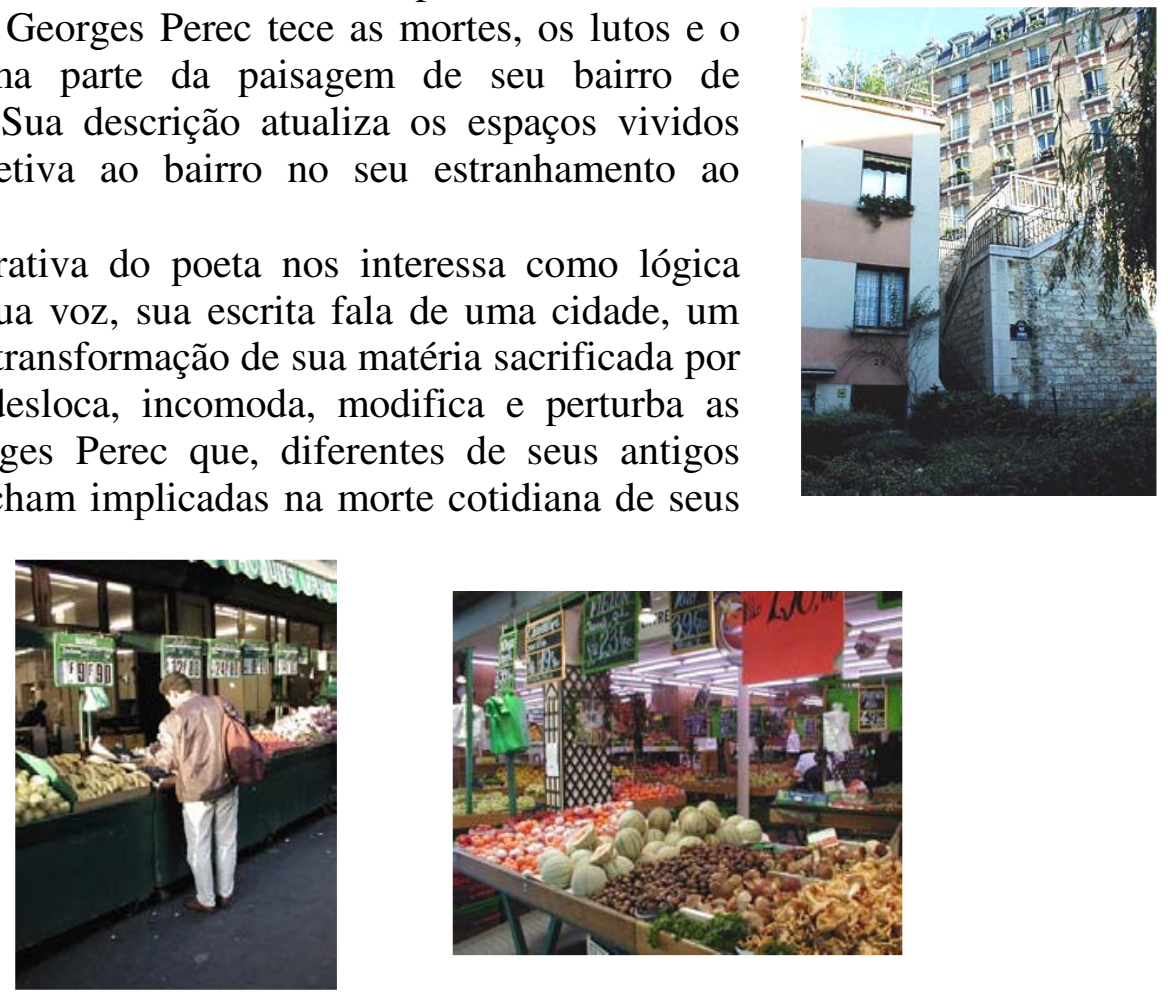

\section{Qual a retórica da caminhada de Perec?}

Ao buscar um reencontro com o bairro e a rua de sua infância ao longo do processo de reurbanização parisiense, Georges Perec se transforma num autêntico narrador da cidade. Sua biografia se mistura às mudanças no bairro, na cidade, sem rupturas precisas do antes e do agora, nem do progresso e do retrocesso tanto quanto as mudanças de sorte de sua vida no bairro organizam o fluxo de sua narração. 
Domingo, 5 novembro 1972

Próximo às 14 horas

O número 1 ainda se encontra lá. $O$ número 2, o 3: cores e confecções "Bom atendimento"; $o$ : Reparos (fechado); o 5: a leitaria se tornou ferragem? $O 6$. cabelereiro. O 7, destruído. O 8 e o 9? O 10: consertos em pele; o 11, destruído; o 12 Selibter; o 13 destruído; o 14: um prédio destruído, uma butique ainda em pé; $o$ 15 inteiramente destruído; o 165? O 17? Bar-porão. O 18: Hotel Constantine, murado; o 19? 20? 21, destruído. 22: Hotel-café. 23? 24, ainda intacto, o 25 uma loja fechada; no 26, janelas muradas. O 27 murado, 28, 30, 36 ainda em pé.

Um gato tigrado e um gato preto no corredor do 24 .

Depois do 27, lado ímpar, mais nada; depois do 36, lado par, mais nada. No imóvel de número 30, outdoor

de Johnny Halliday.

(PEREC, 1989, p. 28 a 31)
Neste ponto, construindo signos e mediações como na estrutura de um lugar-mito, o estilo da escritura de Perec tem uma moldura mental, a memória étnica de uma família judaica, é toda uma estória de perseguição vivida pelos judeus na França Ocupada que ressoa no seu relato bricolado com elementos tirados de lugares-comuns, "uma história alusiva e fragmentária cujos buracos se encaixam nas práticas sociais que simboliza". (DE CERTEAU, 1984, p. 182). Neste sentido, um fato em particular é apontado no documentário: a Rua Vilin, do lado ímpar, dirá o poeta, na altura da casa 49, à esquerda, faz um segundo ângulo. Também em torno da

casa 30. Curvatura esta que vai desenhar um S alongado, mais parecido com os sinais SS. Do lado ímpar, a rua termina na altura dos números 53-55 em uma escadaria, ou melhor, três escadarias que esboçam elas também de forma dupla a sinuosidade (mas menos a forma de um $S$ do que a de um ponto de interrogação ao inverso). (DE CERTEAU, 1984, p. 180).

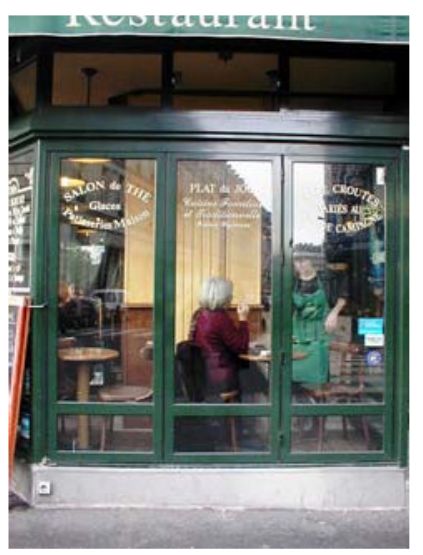

A etnografia nas ruas proposta pelo escritor envolveria, assim, uma "retórica habitante" (DE CERTEAU, 1984, p. 180) através da forma como seu relato alude às estórias vividas nas esquinas, nos becos, nas casas, nas ruas de seu bairro de infância.
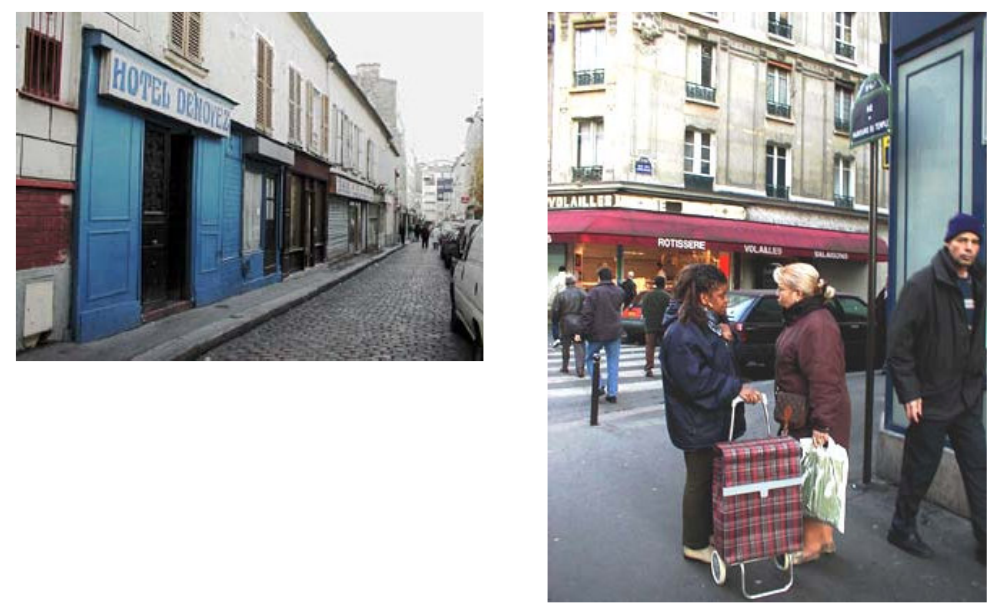

Trata-se sempre de uma narração, encadeando acontecimentos descontínuos que duram na sucessão das palavras, das vozes de habitantes que ao se pensar pensando a cidade, a reinventam como a retórica benjaminiana de "uma escrita da história ao mesmo tempo destruidora e salvadora" (BENJAMIN apud GAGNEBIN, 1999, p. 105), transformação ativa do presente. 
O que aprender com o estilo narrativo adotado por G. Perec para descrever o fluxo das transformações dos espaços limítrofes da Rua Vilin no quartier de Belleville, sua rítmica no fluxo do tempo? Além da ausência de um tom melancólico ou nostálgico, das marcas de uma escritura plena de interrogação, as quais o autor não busca responder, o que torna o relato do poeta muito próximo do etnógrafo é que sua voz narrativa não busca encobrir a matéria perecível do tempo, mas revelá-la, descrevendo sua inscrição dolorosa na alma do escritor. Como ele próprio afirma em outra obra, W ou Les souvenir d'enfance, a escrita se revela não apenas como lembrança da morte de seus pais, mas como a afirmação da sua vida. ${ }^{8}$

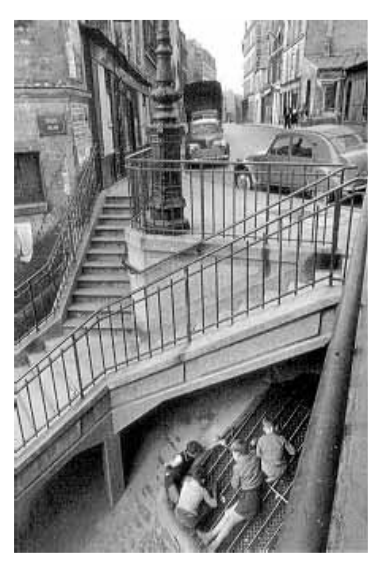

O enunciado narrativo das duas obras, aqui, citadas de Georges Perec restitui, por seu próprio estilo lacunar, a vertigem do viver urbano, o processo de destruição/criação de uma cidade. O processo de desterritorialização de suas lembranças de infância cede à sua experiência da caminhada como reinvenção de tradições do viver a cidade que se entrecruzam. $\mathrm{O}$ medo benjaminiano de se perder, de se esfacelar junto ao pó da ruína em esquecimento ("o número 16? 19? 20? 21 destruídos"), a paisagem fragmentada da Rua Vilin convida ao resgate do deslocamento a pé, aderindo as deambulações do poeta.

\section{Tempos narrados e espaços imaginados: reconstituindo a Rua Vilin a partir de uma etnografia de rua em Belleville}

Viajantes, estrangeiras na cidade de Paris, o estranhamento é pouco radical, a aventura é urbana, somos nativas em contextos citadinos e seguimos a aprendizagem de Georges Perec sobre o infra-ordinário na forma como se pode habitar a cidade e suas ruas. Estamos agora na Rua Villin, em torno da qual se desenrola a estória do documentário sobre Georges Perec.

É, portanto, na observação e descrição rítmica da pluralidade de instantes de uma ação ou estado de alma vivido pelo próprio poeta que o cineasta pretende apreender o drama da duração na obra de Georges Perec, ou seja, a dinâmica temporal que arranja tensão entre o desejo de

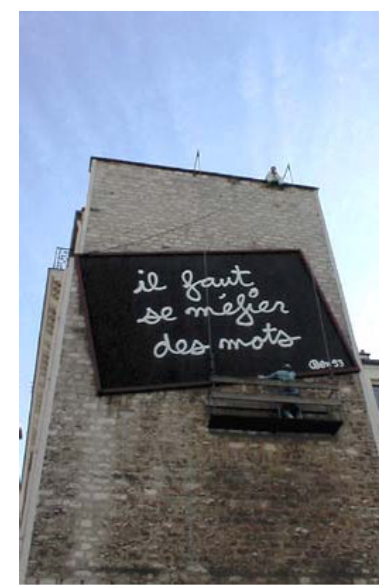
transformação da paisagem urbana de uma parte da comunidade parisiense e a vontade de permanência das lembranças de seu bairro de infância. ${ }^{9}$

\footnotetext{
${ }^{8}$ DUPUIS, Joachim Disponível em: http://www.interdits.net/2003aout/perec.htm. Acesso em: 3 de maio 2004.

9 "Mas o que constitui a localização social da memória não é somente uma instrução histórica; é bem mais uma vontade de futuro social. Todo pensamento social está voltado para o futuro. Todas as formas do passado, para criar pensamentos verdadeiramente sociais, devem ser traduzidas na linguagem do futuro humano". (BACHELARD, 1988, p.48).
} 
No documentário En remontant la rue Vilin, explorando a riqueza de mais de 200 fotografias pertencentes ao acervo pessoal de G. Perec, onde o escritor registrou a transformação lenta dos espaços desta rua de sua infância até o seu completo desaparecimento dando lugar ao Jardim de Belleville, o diretor Robert Bober opta por um documentário memorialista, valendo-se da leitura "in off" (voz de Marcel Cuvelier) de textos do livro Recits d'Ellis Island, escrito pelo poeta e publicado em 1980, tendo ao fundo a bela música de Denis Cuniot.

A estrutura narrativa adotada pelo documentário sugere questões epistemológicas sobre as relações entre o espaço e a memória no mundo urbano contemporâneo: Por que descrever uma rua qualquer de uma grande cidade? Por que contar nossas lembranças de tempos de outrora, que não mais poderão ser retomados, uma vez que a paisagem original de nossas reminiscências já não mais existe? Por que temos a necessidade de nos reconhecer num lugar habitado por outro tempo que não mais aquele por nós vivido? Como entender seus traços atuais? Como recuperar no espaço presente as pistas dos lugares do passado? Como "ler" os indícios dos tempos de outrora no que o tempo presente não nos revela de imediato? É possível restaurar os vestígios de nossas lembranças a partir da fotografia? Mas

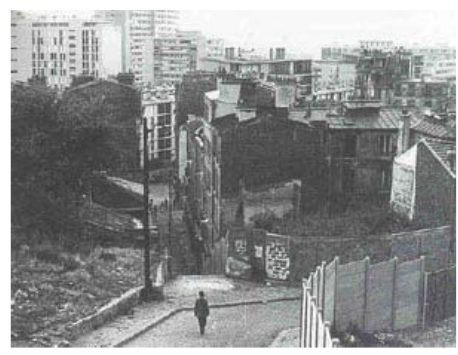
se através da fotografia podermos restaurar as pistas do tempo, é possível prolongar a sua existência, encenando-o através do filme? No roteiro do filme, o diretor propõe três histórias que poderiam começar este documentário, interessante é observar que tais histórias articulam 04 formas de registro imemorial do tempo, ou seja, a oralidade, a escrita, a fotografia e o filme, cada qual participa à sua maneira da estrutura da obra.

\section{A intriga do filme, En remontant la Rue Vilin, sob o enfoque de três modalidades de configurações narrativas}

1) As imagens do tempo do mundo

A primeira poderia começar pela localização de uma pequena Rua de Mellimontant em Paris, com $244 \mathrm{~m}$ de comprimento e $8 \mathrm{~m}$ de largura cruzando entre outras com a rua Julien. Começa na altura do 29, rua des Couronnes, onde toma logo uma forma de S invertido. Seguindo-se este caminho chega-se até a rua Piat número 21.

Nesta narrativa fílmica, as fotos de acervo se sucedem cronologicamente, nomeando e localizando as casas e estabelecimentos dispostos ao longo da Rua de Mellimontant. Escadas, terraços, residências, cafés, hotéis, tabacarias, etc. No alto do bairro de Belleville, as imagens fotográficas desvendam uma panorâmica de Paris, remetendo aos inúmeros filmes clássicos que tiveram este território como espaço de locação de cenas. Esta primeira historieta recupera a história oficial da rua e de sua nomeação, em 1863, como Rue Villin, em homenagem ao arquiteto do mesmo nome que ali fora proprietário e prefeito. Esta situação urbana se mantém até 1982, quando a rua, então, é avaliada pelos órgãos de higiene pública como insalubre, sendo as moradias de números 16, 18, 22 e 24 condenadas à extinção. A destruição das residências desfigura a paisagem urbana local ao transformar a Rua Villin em lugar povoado por cimentos e ruínas num vazio de vida cotidiana a espera de novos projetos. 
2) O tempo subjetivo das imagens fotográficas

A segunda historieta inicia-se pela reforma urbana de Belleville nos anos 1980. Indica

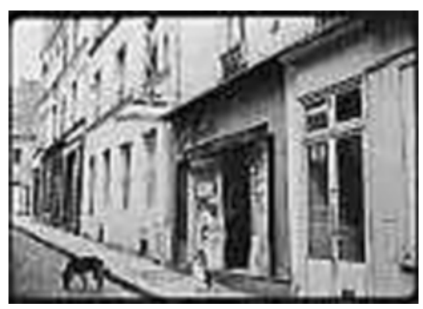
as definições cardinais e matemáticas do "quartier", resituando a Rua Villin nos pés desta colina que, na época, conhece uma importante política de reurbanização dando lugar ao Jardim de Belleville como mostram as imagens fotográficas coloridas mais recentes que documentam uma inauguração ocorrida em 1988. De acordo com esta historieta, este antigo espaço deteriorado do bairro Belleville, resultado da destruição dos antigos casarios, adquire nova função transformando-se num parque-jardim, e cujo paisagismo sofisticado de alamedas, fontes, recantos e passeios, é rapidamente re-apropriado pelos habitantes do lugar e alguns turistas.

Do lugar antes e do lugar agora, o documentário revela, então, a Rua Vilin pela ótica de inúmeros fotógrafos que captaram este mesmo local, em suas lentes fotos que relatam uma vida tranqüila no passado com personagens singulares nos tempos dos lampiões a gás. Novamente, o documentário retorna ao registro da demolição, das ruínas, do vazio deixado na paisagem de Belleville pela destruição daquelas vetustas moradas, agora, entretanto, fixando o olhar do espectador numa imagem, em especial, uma casa com janelas muradas, com uma inscrição quase apagada "Coiffure

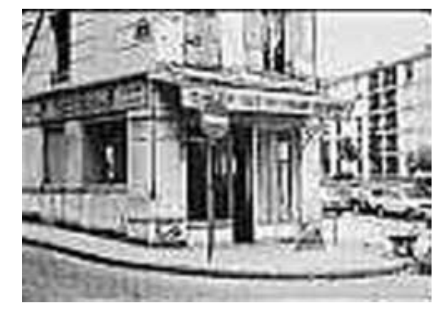
Dame".

\section{3) A duração}

A terceira e última historieta retoma todas as duas anteriores, re-situando-as no interior das lembranças de um morador local, o escritor e poeta Georges Perec e de sua tentativa de compreender os meandros da passagem do tempo a partir do registro sistemático das suas formas na paisagem urbana parisiense de sua infância. Somos, então, convidadas a percorrer o processo de escrutínio do tempo pelo qual Georges Perec deixa-se levar no sentido da captura da agonia e morte desta rua de sua infância: durante sete anos (1969-1975), uma vez ao ano, sistemática e religiosamente, o escritor percorria as ruas do bairro e em especial a Rua Vilin, anotando detalhadamente suas

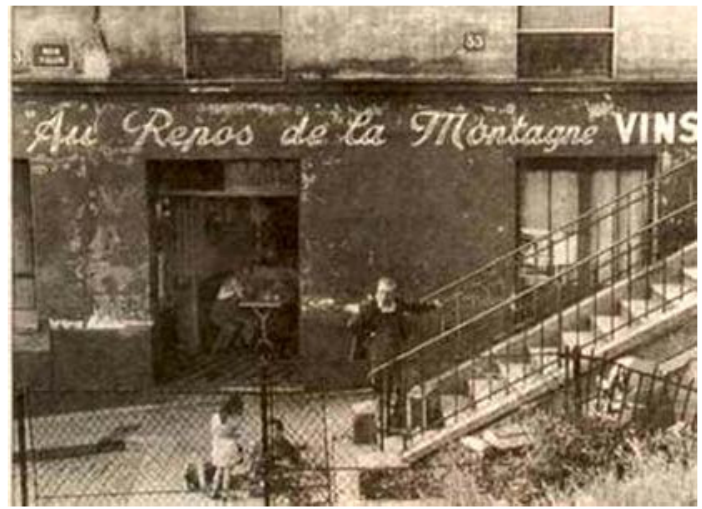
modificações, acompanhado de um fotógrafo amigo que registrava detalhes e fragmentos da paisagem local, provavelmente a partir de conversas e comentários entre eles. O projeto era a publicação de um livro, cujo nome provisório era "Os lugares" (Les lieux), reunindo fotos e comentários escritos, retratando os lugares de suas memórias em Belleville a partir da memória dos lugares. 


\section{$O$ vivido evocado através das obras escritas e a narrativa fílmica de $R$. Bober}

O projeto aqui mencionado do escritor Georges Perec durou 12 anos, de 1969 a 1980, e comporta 288 textos guardados ano a ano em envelopes, por ele catalogados e indexados. Uma sistemática de trabalho que é relata na obra Espèce d'Espace (1974/2000). Nela, Georges Perec, tomando a rua como espaços habitados por micro-eventos inventariados e inventados, anotava, de tempos em tempos, as marcas das destruições e renovações urbanas de determinados lugares como forma de decifrar um pedaço da cidade, deduzir suas evidências, ler o que o tempo nela deixava escrito.

Espèce d'Espace é uma obra que revela uma escrita detalhista, construída a partir de uma posição assumida por seu autor diante da sua percepção espacial do escoamento do tempo. Conforme afirma com veemência o poeta (PEREC, 1974/2000, p. 16), viver é passar de um espaço a outro, tentando o mais que possível não esbarrar em outro. Percorrer o espaço das ruas até que os seus lugares se tornem improváveis para nós, até sentir, por um breve instante, a impressão de se estar numa cidade estrangeira. Com uma lucidez ímpar, o escritor propõe-se a documentar a paisagem urbana parisiense a partir dos ritmos de um triplo envelhecimento, "dos lugares", "de minhas memórias" e "dos meus escritos".

As "anotações de campo" são guardadas em envelopes, escritos a mão ou datilografados, e cujas páginas escritas dialogam com o conteúdo de ingressos, ticket de metro, entradas de cinema, prospectos e fotos destes lugares. Fotografias feitas por um amigo ou uma amiga, a seu pedido ou não, e que G. Perec "deslizava" para dentro de um envelope, sem olhar. Páginas adormecidas e documentos dispersos deixados ao sabor do tempo, envelhecendo, sem qualquer referência à obsessão de uma análise minuciosa por parte do escritor.

Neste esforço de Georges Perec para enquadrar o tempo dentro de um registro, escrito ou fotográfico, apenas uma foto lhe interroga constantemente. A fotografia da casa 24, Rua Vilin. Uma velha morada contendo uma indicação quase apagada pelo tempo. "Coiffure Dame". Trata-se da casa materna, capa do seu livro "W", demolida no dia que se seguiu a sua morte, 24 março de 1982. Um vestígio do tempo que o

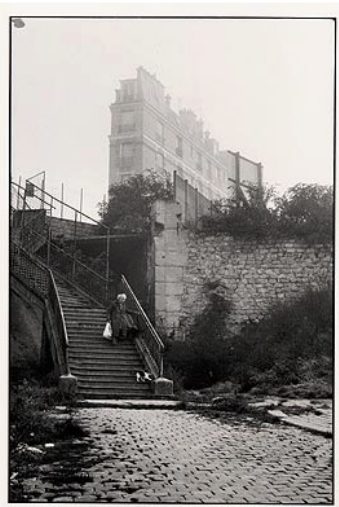
escritor pensa restaurar no interior de suas lembranças, mas que, como veremos, lhe escapa e o trai, relevando-lhe, mais tarde, sua verdadeira face, "Coiffure de dame".

No documentário, Robert Bober explora em um fluxo narrativo os detalhes dos registros fotográficos deixados por Georges Perec ao abrigo do tempo como de suas descrições escritas. A câmera penetra nas imagens fotográficas, na tentativa de descobrir sua duração, de decifrar os desígnios do tempo capturado no instante fotográfico. Num diálogo entre múltiplas textualidades, da cinematográfica à fotográfica, sem conseguir reter as fissuras do tempo, e na busca de restaurar a totalidade da experiência de Georges Perec, 
o documentário recorre às observações dos seus cadernos de campo, posteriormente publicadas na forma de livros. Apoiando-se na intertextualidade que se cria na cooperação entre filme e fotografia, o documentário tece os escritos do poeta como referência do mundo real. A voz in off desperta os pensamentos escritos do poeta e somos, então, na continuidade do fluxo narrativo criado por Robert Bober, convidados a mergulhar nas fotografias da Rue Villin através dos escritos de Georges Perec. Descrições minuciosas ou observações anedóticas, as anotações sobre a paisagem da rua observada, em seus múltiplos pontos, se sucedem revelando o método deste autor: olhar, anotar, registrar o lugar, a hora, o tempo, o acontecimento. As evidências escritas, anotadas no papel, no documentário tomam forma, a partir da exploração da imagem-tempo fílmica em sua insistência em movimentar os rastros e fragmentos de imagens como peças de um jogo, ou, de jogos de memória.

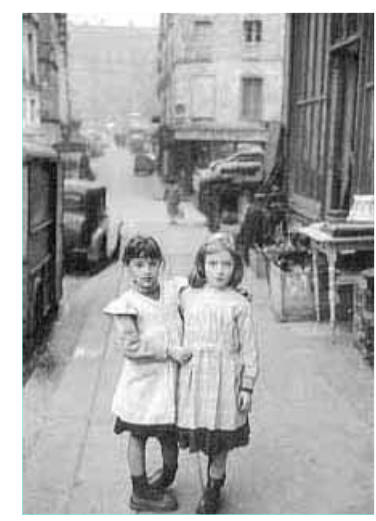

No filme, o diretor explode o caráter analógico das imagens fotográficas da Rua Villin, forçando-as ao rompimento com seu fluxo de verossimilhança com o real, na pretensão da imagem fílmica em alcançar umas representações diretas do tempo, fazendo com que todas as imagens (orais, textuais, fotográficas) nas quais se apóia o documentário reajam umas sobre as outras. Neste ponto, o documentário de Bober é fiel à poética da obra escrita de Perec, pois a linguagem fílmica explora um texto que bricola anotações e comentários com fotos, cujas amarrações exploram as camadas de tempo da própria "experiência etnográfica" de Perec, segundo suas sobreposições em sequiências verticais e horizontais.

O documentário, finalmente, ganha corpo no interior de uma atitude poética de representação do mundo dada a partir de um sistema de textos Não é mais na alusão à realidade do mundo das transformações da Rue Villin, que no filme ganha força, mas precisamente na forma como que ele torna difícil a separação entre a referência do mundo dos textos de Georges Perec e a referência ao "texto" do mundo observado pelo poeta. O documentário recria, assim, a obra e o pensamento deste escritor, buscando desvendar o eco de suas palavras contidos na construção do "texto" fílmico. Nele, podemos observar a retórica adotada por G. Perec em sua escrita, quando o poeta começa seu texto com a frase "a rua Vilin começa no número 29..." para, logo após, inserir a descrição de cafés, hotéis, residências que se sucedem. O fluxo narrativo é novamente interrompido quando o escritor retorna no tempo, fixando-se, então, no numero 24 , a casa onde viveu. Como se estivesse numa sala de montagem, Georges

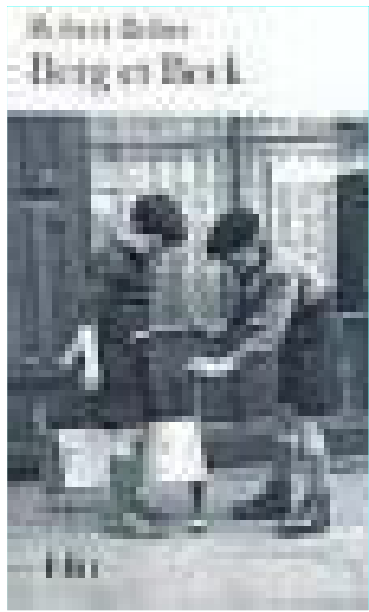
Perec constrói seu registro escrito de memórias em raccords, tornando a relação de suas lembranças da Rua Villin com a paisagem urbana parisiense quase não-localizável, deixando extrair de seus escritos suas relações com o tempo. Ao mesmo tempo em que anota detalhes observados na evidência física da paisagem urbana, Georges Perec se indaga sobre os transeuntes, seus estilos de ser e viver, seus percursos, suas identidades (PEREC, 1974/2000, p. 104). 
Atento aos traços deste movimento, a montagem do documentário retoma os registros escritos de Georges Perec, do ano de 1972, associando suas palavras às imagens fotográficas de seu acervo pessoal e explorando seus traços com expressão singulares de uma matéria em movimento. Num primeiro momento, o quartier, onde se situa a Rua Villin, é descrito por Bober a partir de um enquadramento cronológico do tempo, através do agrupamento progressivo das anotações feitas por G. Perec do espaço até sua feição atual, onde desponta a presença da casa de sua infância ainda que boa parte da rua tenha já se modificado e o prédio ao lado dela já tenha sido demolido. Como já foi comentado, o roteiro da estória narrada deste ponto em diante irá se desdobrar em mais outras duas formas de estrutura narrativa através da enunciação dos fatos, situações e acontecimentos em diversas modalidades diferenciadas de controle simbólico do tempo.

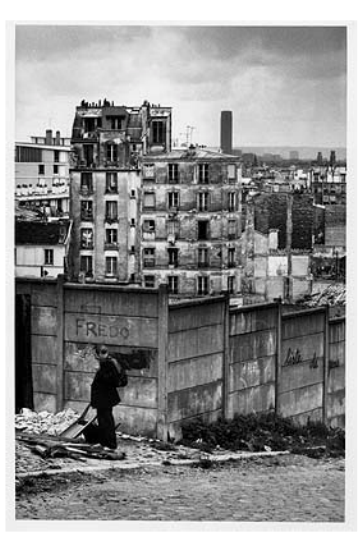

Da causalidade material do tempo do mundo marcado pelas transformações físicas da Rua Vilin à causalidade formal do tempo subjetivo das lembranças de G. Perec, o documentário se configura progressivamente como um ensaio que explora os limites da imagem filmica. Os movimentos interrogantes e teorizantes da câmera sobre as fotografias se destacam pelo poder que possuem de operar relações pelo modo como podem penetrar nos acontecimentos do extra-campo. Neste trajeto, fica, então, evidente que o documentário procura contemplar, na sua própria estrutura narrativa, o desvendamento das intenções inconscientes de Georges Perec por detrás das recordações da rua onde viveu a sua infância. Lembranças truncadas do passado de perseguição e deportação de seus pais para os campos de concentração na Alemanha, que o diretor alude no documentário de Bober como forma de luta de Georges Perec por uma descrição do infra-ordinário onde se desvenda uma linguagem cifrada de acontecimentos reprimidos de sua história familiar. Acontecimentos clandestinos à consciência do poeta, mas que cuja escrita, no afã de nomear as coisas mortas, insinua e que, finalmente, a imagem filmica retira do esquecimento.

Neste momento temos clareza que a intriga do documentário se sustenta pela sua relação que une a imagem filmica a uma reflexão sobre o tempo, instaurando um pensamento que se pensa no desenrolar subconsciente das imagens. Em suas relações com o pensamento a imagem filmica permite a Bober converter os pensamentos ocultos de Georges Perec sobre a sua infância na Rua Vilin em conteúdo manifesto de seus sonhos de adulto. Num primeiro momento, o documentário deixa-se levar pelo ato falho cometido por Georges Perec que insiste em confundir o nome "Gelibter" escrito na fachada de uma das residências da Rua Vilin com "Selibter". A substituição do G pelo $\mathbf{S}$ na escrita do poeta é inúmeras vezes retomada no documentário em alusão a um desejo de verdade que é estranho ao próprio poeta. O cineasta, operando com a imagem filmica, insiste que a escrita de Georges Perec parece articular uma verdade que o próprio autor desconhece. Ela comporta fragmentos de sua memória da Rua Villin que lhe escapam na forma como se apresentam como imagens obscuras, opacas do passado.

Num dado momento, a narrativa do documentário adere ao desejo inconsciente do poeta-etnógrafo em restaurar as partes perdidas de suas imagens de infância da Rua Villin, numa tentativa de desvendar o que Georges Perec não pode ter "lido" nos seus escritos e nem visto nas fotografias guardadas consigo. O documentário nos provoca interrogações: que desejos inconscientes movem este ato falho da escrita de Georges Perec que insiste em 
trocar o $\mathbf{G}$ pelo $\mathbf{S}$ ? Na tentativa de responder a esta indagação, o documentário explora, a partir dos efeitos de raccords o processo de imersão do olhar do espectador nas imagens fotográficas da paisagem antiga da Rua Villin, criando nelas buracos, introduzindo descompassos, abrindo vazios.

Escrutinando os escritos do poeta, o documentário nos mostra os mesmos lapsos. Em 1979, Georges Perec, ao percorrer Rua Vilin, insiste em descrevê-la como uma curva em S, o mesmo $\mathbf{S}$ que o poeta insiste em atribuir na escrita em Gelibter (Selibter). Novamente o documentário, explorando os flash-backs, alude à traição da memória de Georges Perec quando adota o registro do significante $\mathbf{S}$ como forma de proteger o poeta da dor de suas reminiscências. Numa aventura no interior do inconsciente de Georges Perec, a narrativa filmica adere a uma arqueologia da letra $\mathbf{S}$ na vida do poeta, e brincando com sua forma, remonta desde as suas experiências de aprendizagem desta letra no hebraico, até que faz do prolongamento da Rua Villin, como um duplo $\mathbf{S}(\mathbf{S S})$, quando de fato, o desenho que adota esta rua é de um duplo $\mathbf{S}$, mas ao contrário. É desta forma que o documentário assinala que lenta agonia que antecede a destruição da casa materna de Georges Perec encobre a memória habitada de suas lembranças da perda de seus pais na cidade de Paris, ocupada pelos alemães.

É desta forma que as sobreposições temporais da escrita de Perec não aludem aos atos de destruições dos locais da sua infância como atos da violência urbana. Isto porque, no seu relato das destruições da antiga paisagem da Rue Vilin, o poder da violência procede do "feliz esquecimento" (NIETZSCHE e BENJAMIN apud

Escrever: tentar meticulosamente reter qualquer coisa, de fazer emergir qualquer coisa : arrancar algumas lascas precisas do vazio que se abre, abrir, em algum lugar, um veio, um traço, uma marca ou qualquer sinal.

(PEREC, 1974/2000, p. 180).

GAGNEBIN, 1999, p. 110) do trauma da perda do pai morto em II Grande Guerra, da deportação da mãe para os campos de Auschwitz. Um acontecimento resgatado nos acervos sobre os deportados. Com isto o documentário recorre aos efeitos em flash back, indo visitar o ritual da leitura dos nomes dos familiares judeus de Georges Perec, nomes inscritos na tumba funerária, reverberação dos laços de pertencimentos familiares que ilustram os seus lapsos de memória.

O projeto que alcunhamos de "etnografia de rua" de Perec termina em 27 de setembro de 1975, na escrita de um último texto. (PEREC, 1989, p. 31). Ano em que um fotógrafo anônimo realizou 9 fotografias que se unidas ilustram minuciosamente uma panorâmica da rua resgatando o cenário onde um menino faz seu percurso atendendo um chamado maternal imaginário.

$$
* * *
$$

De nossa parte, fomos e somos usuárias da cidade de Perec, problematizando nossa caminhada e nossa leitura de sua obra como pesquisa ao desaparecimento dos rastros como indica Benjamin em "Experiência e Pobreza". Re-atualizamos o percurso mapeado pelos escritos de Perec. A qualidade epistêmica, os valores cognitivos da caminhada e das leituras não são mesuráveis. Nem os debates freqüentes no ilustre apartamento alugado no 29, rue de la Fontaine au Roi, nem as anotações que registram ou as fotos que classificamos, nem as fichas de leitura de seus livros nos dão qualquer certeza das fronteiras retóricas de um lugar ainda genérico. Mistura de fatos vistos, ouvidos, discutidos escritos, ainda "estando 
lá”, revividos na re-escrita interpretativa estando aqui. A aprendizagem é o olhar etnográfico que se coloca como interpretação, identidade narrativa que constitui a vida em movimento, deslocamento.

Esforço simmeliano de "sempre escavar as camadas mais profundas, em uma interpretação" (WAIZBORT, 2000, p. 29) configurando a arte narrativa, que mistura uma pluralidade de sentidos, e como requer Nietzsche, uma constelação, complexo de sucessões, mas também de coexistências (apud WAIZBORT, 2000, p. 30). Das lembranças (noème) e rememorações (noèse), Georges Perec reinventa o lugar na narrativa tecida. A poética da escrita fabula o tempo, vibrando sons e estetizando formas que resituam o personagem, agenciam os fatos na ipseidade do ato autoritário do autor criativo, na arte do saber-fazer da escrita que preenche o mundo de significações e razões para imaginar.

« Écrire : essayer méticuleusement de retenir qualque chose, de faire survivre quelque chose : arracher quelques bribes précises au vide qui se creuse, alisser, quelque part, un sillon, une trace, une marque ou quelques signes ». (PEREC, 1974/2000, p. 180).

\section{REFERÊNCIAS}

BACHELARD, Gaston. (1989) La poétique de l'espace. Paris, Puf.

BACHELARD, Gaston. (1989) La erre et les rêveries du repos. Paris, José Corti.

BAKHTIN, Mikhail. (1992) Estética da criação verbal. São Paulo, Martins Fontes. BAUDELAIRE , Charles. (1861) Tableaux parisiens. Les fleurs du mal. Paris, PouletMalassis.

BAUDELAIRE , Charles. (1869) Le spleen de Paris. Paris, Asselineau et Banville. BENJAMIN, Walter. (1982) Das Passagen-Werk, escrito em 1939 à Paris e publicado em 1982.

BENJAMIN, Walter. (1939) Sur quelques thèmes baudelairiens, in Zeitschrift für Sozialforschung, VIII, 1, 2 Paris.

CALVINO, Italo. (1990) As cidades invisíveis. São Paulo, Companhia das Letras.

CANEVACCI, Massimo. (1993) A cidade polifônica. São Paulo, Studio Nobel.

DE CERTEAU, Michel. (1984) A invenção do quotidiano. Petrópolis, Vozes.

DEBRAY, Régis. (1992) Vie et mort de l'image. Paris, Gallimard.

DURAND, Gilbert. (1988). A imaginação simbólica. São Paulo, Cultrix.

ECKERT, Cornelia e ROCHA, Ana Luiza Carvalho da. (1998) "A interioridade da experiência temporal do antropólogo como condição da produção etnográfica”. In: Revista de Antropologia. Volume 41, número 2. São Paulo, Faculdade de Filosofia, Letras e Ciências Humanas, Universidade de São Paulo. pp. 107 à 135.

ECKERT, Cornelia e ROCHA, Ana Luiza Carvalho da. (2001) "Imagens do tempo nos meandros da memória: por uma etnografia da duração”. In: Koury, Mauro Guilherme Pinheiro (Org). Imagem e Memória, ensaios em Antropologia visual. Rio de Janeiro, Garamond.

GEERTZ, Clifford. (1989) El antropologo como autor. Barcelona, Paidos Studio.

HALBWACHS, Maurice. (1990). A memória coletiva. SP, Vértice Editora Revista dos tribunais..

L'ÉCOLE DE CHICAGO. (1974/2000) Naissance de l'écologie urbaine. Paris, Aubié. LEVI-STRAUSS, Claude. (1998) Tristes Trópicos, São Paulo, Companhia das Letras. 
MAFFESOLI, Michel. (1985) "Le paradigme esthétique. La sociologie comme art". In: Sociologie et Société. Vol. XVII, Número 2, octobre, pp. 33 à 39, Montréal, Ceaq.

MAUSS, Marcel. (1974/2000) "Ensaio sobre a dádiva". In: Sociologia e Antropologia. Volume II. São Paulo, EPU/EDUSP.

PETONNET, Collete. (1982) "L'observation flottante, l'exemple d'un cimetièreparisien". In: Revue L’Homme, Octobre/Décembre, numéro XXII 4, pp. 37 à 47, Paris, CNRS.

PROUST, Marcel. (1954) Le temps retrouvé, vl. VIII de A la recherche du temps perdu. Paris, Gallimard. RICOEUR, Paul. (1994) Tempo e Narrativa. Vol I, SP, Papirus.

RICOEUR, Paul. (1996) Soi-même comme un autre. Paris, Ed. du Seuil.

SANSOT, Pierre. (1972) Poétique de la ville. Paris, Klincksick.

http://perso.wanadoo.fr/jb.guinot/pages/Perec1.html\#ouvrages

Alphabets (14) dernière mise à jour : 1er février 2003

Beaux présents, belles absentes (3) dernière mise à jour : 30 avril 1998

La Boutique obscure (7) dernière mise à jour : 16 février 2003

Un Cabinet d'amateur (19) dernière mise à jour : 5 juin 2003

Cantatrix sopranica L (4) dernière mise à jour : 17 février 2000

53 jours (17) dernière mise à jour : 14 décembre 2002

Les Choses (38) dernière mise à jour : 7 juillet 2003

La Clôture (6) dernière mise à jour : 16 février 2003

La Disparition (54) dernière mise à jour : 29 novembre 2003

Entretiens et Conférences (1) dernière mise à jour : 24 novembre 2003

Espèces d'espaces (21) dernière mise à jour : 4 janvier 2004

Un Homme qui dort (24) dernière mise à jour : 7 juillet 2003

L'infra-ordinaire (13) dernière mise à jour : 7 juillet 2003

Je me souviens (20) dernière mise à jour : 29 novembre 2003

Je suis né (1) dernière mise à jour : 30 avril 1998

Jeux intéressants, Nouveaux jeux intéressants (0)

J.R : tentative de saturation onomastique (1) dernière mise à jour : 8 mai 1998

L.G. (1) dernière mise à jour : 30 avril 1998

La littérature potentielle. Atlas de littérature potentielle (23) dernière mise à jour : 5 juin 2003

Les Mots croisés (4) dernière mise à jour : 30 avril 1998

ouvrages non publiés / projets (12) dernière mise à jour : 20 septembre 2003

Penser/classer (5) dernière mise à jour : 24 novembre 2003

Perec/rinations (0)

Petit traité invitant à la découverte de l'art subtil du Go (0)

Quel petit vélo à guidon chromé au fond de la cour ? (8) dernière mise à jour : 5 juin 2003

Récits d'Ellis Island (5) dernière mise à jour : 29 novembre 2003

Les Revenentes (6) dernière mise à jour : 8 mars 2003

Tentative d'épuisement d'un lieu parisien (2) dernière mise à jour : 30 avril 1998

Théatre (5) dernière mise à jour : 25 mai 2002

varia (26) dernière mise à jour : 5 juin 2003

La Vie mode d'emploi (166) dernière mise à jour : 4 janvier 2004

Voeux (0)

Le Voyage d'hiver (4) dernière mise à jour : 29 novembre 2003

W ou le souvenir d'enfance (106) dernière mise à jour : 20 septembre 2003

What a man ! (2) dernière mise à jour : 13 mai 1999 


\section{TRANSVERSES}

bibliographies (8) dernière mise à jour : 29 novembre 2003

de la littérature, de l'écriture (136) dernière mise à jour : 4 janvier 2004

nombres (10) dernière mise à jour : 26 octobre 2002

musique, peinture (30) dernière mise à jour : 24 novembre 2003

\section{TRACES}

biographies, autobiographie, monographies (60) dernière mise à jour : 4 janvier 2004

pistes (125) dernière mise à jour : 20 septembre 2003

http://www.associationperec.org/

Visite lê 25 mai 2004 par Cornelia Eckert

\section{ETUDES EM LIGNE SUR GEORGES PEREC}

Les résumés des Séminaires Georges Perec

Le catalogue de la bibliothèque de Georges Perec. (format pdf)

Allusions à la bande dessinée dans la Vie mode d'emploi. in Adamantine. Peter Baker.

Georges Perec's 'negative' autobiography. Townson University.

Cécile de Bary. Le trompe-l'oeil, image usée d'un usage perecquien de la fiction.

Communication au colloque en ligne "Frontières de la fiction", organisé par Fabula en mars 2000.

Cécile de Bary. Les dessins dans le genèse de W ou le souvenir d'enfance. Le Cabinet d'amateur. Août 2000. Howard.S. Becker. Sociologie, sociographie, Perec, et Passeron. Colin Bell. Perec's Les Revenentes : the word made flesh. Trinity College. Dublin [fichier pdf]

Dominique Bertelli. L'invention du cinquante-trois. Le Cabinet d'amateur. ${ }^{\circ}{ }^{1}$. Printemps 1993

Nicole Bilous. Les choses dans Les Choses. Le Cabinet d'amateur. ${ }^{\circ}{ }^{1}$. Printemps 1993. Guy Chouraqui. Une machine à écrire en trompe-l'oeil : La vie mode d'emploi, de Georges Perec. Communication au colloque de Cerisy

Mathématiques et psychanalyse, septembre 1999

Isabelle Dangy. Le bonheur du crime. Le Cabinet d'amateur. Février 2002. Joachim Dupuis. La pièce manquante .Août 2003

Juan Gregorio Aviles. Georges Perec : Bajo el brillo de Las Cosas. Texte paru initialement in "Espinosa" $\mathrm{n}^{\circ} 1$. Murcia 2001, et transmis par l'auteur.

Juan Gregorio Aviles.Un avatar para el deseo. Microfisuras. n 19. 2002. et transmis par l'auteur.

Juan Gregorio Aviles. Tres miradas para el Viajero (Montaigne, Montesquieu, Perec).

Caracteres literarios $n^{\circ} 6$. et transmis par l'auteur. Paul A. Harris. Life from the other side :

time in the shadow of the sign. Loyala Marymount University. (à propos du chapitre 99 de la Vie mode d'emploi)

Marie-Pascale Huglo. Du palimpseste à l'écho, Un homme qui dort. Le Cabinet d'Amateur. Janvier 2002.

Maria-Eduarda Keating.Traduction et trompe-l'oeil : les versions ibériques de La vie mode d'emploi de Georges Perec. Revue

Meta.Volume 46. $\mathrm{n}^{\circ}$ 3. 2001.

Bernard Magné. Construire l'anodin : les Deux cent quarante-trois cartes postales en couleurs véritables. Le Cabinet d'amateur. ${ }^{\circ} 1$. Printemps 1993 
Bernard Magné et Pierre di Sciullo. Les tristes épousailles d'Andin Basnoda. Le Cabinet d'amateur. $\mathrm{n}^{\circ} 1$. Printemps 1993

Bernard Magné. De l'exhibitionnisme dans la traduction. A propos d'une traduction anglaise de la Vie mode d'emploi. Revue Meta $\mathrm{n}^{\circ} 3$

vol. 38. Presses de l'Université de Montréal. Septembre 1993

Bernard Magné. Esquisse d'une typologie de la littérature combinatoire. Décembre 2000.

Bernard Magné. Le metatextuel perecquien revisité. Le Cabinet d'Amateur. Août 2002.

Bernard Magné. Couples modes d'emploi. Le Cabinet d'amateur.Juin 2003.

Andréa Martines. La letteratura combinatoria - Georges Perec.

Warren Motte. Reading Georges Perec. Context, a forum for Literary Arts and Culture. $\mathrm{n}^{\circ} 11$. 2003. Marc Parayre. Perec réécrivain. Le Cabinet d'Amateur. Février 2003.

Christelle Reggiani. La rhétorique de l'invention de Raymond Roussel à l'Oulipo : résumé. Christelle Reggiani. Perec, une poétique de la photographie. Le Cabinet d'amateur. Mars 2001.

Christelle Reggiani. Epuisement du roman et expérience du temps dans Un Cabinet d'amateur. Le Cabinet d'amateur. 2002. Mireille Ribière. En parallèle : rencontre (" Alphabets pour Stämpfli "). Le Cabinet d'amateur. n 1. Printemps 1993

Régine Robin. Un projet autobiographique inédit de Georges Perec : l'Arbre. Le Cabinet d'amateur. $\mathrm{n}^{\circ}$ 1. Printemps 1993

Peter Ronge. Les Revenentes, autre cas de réécriture percquienne ? Le Cabinet d'amateur. Février 2003

Dominique Rosse. Disparition/Réapparition/Identité. La recherche de l'intime chez Georges Perec. Le Cabinet d'amateur. Novembre 2000.

Rémi Schulz. Le secret de La Vie, père C ?.Septembre 2003. Rémi Schulz. Le jeu de La Vie. Septembre 2003.

Rémi Schulz. Pas de palier pour Percival. Septembre 2003. Rémi Schulz. Sur le clivage des W et des X. Novembre 2003. Rémi Schulz. Le don de W. Novembre 2003.

Michel Sirvent. An Auto-bi-graphy. W ou le souvenir d'enfance or the Space of the Double Cover . The Journal of 20th Century

Contemporary French Studies. 1/2 . 1988.

Myriam Soussan. La mémoire vivante des lieux : Georges Perec et Robert Bober. Le Cabinet d'Amateur. Décembre 2000.

Pascal Tremblay. Les Lieux d'une fugue de Georges Perec : les processus du souvenir et de l'écriture comme données métatextuelles. Revue Calliope. Canada. 2000.

Pascal Tremblay. Perec et le lecteur : la construction d'une oeuvre par le jeu. Janvier 2002.

Sylvie Ullmann . Georges Perec : De la page à la lettre. (article ayant disparu)

Sylvie Ullmann. Georges Perec : Les lieux de l'écrit. (article ayant disparu)

Vincent Verselle. Quel mode d'emploi ? Eléments de sémiotique pour un traitement axiologique des personnages dans La Vie mode d'emploi, de Georges Perec. Mémoire de Licence. Université de Lausanne. (page ayant disparu). 